\title{
Electron Transfer in Microemulsion-based
}

\section{Electrolytes}

Jing Peng I,2, Nelly M. Cantillo ${ }^{2}$, K. McKensie Nelms ${ }^{3}$, Lacey S. Roberts ${ }^{2}$, Gabriel Goenaga ${ }^{2}$, Adam Imel ${ }^{2}$, Brian Andrew Barth ${ }^{2}$, Mark Dadmun ${ }^{4}$, Luke Heroux ${ }^{5}$, Douglas G. Hayes ${ }^{2,3}$ and Thomas Zawodzinski, ${ }^{2 *}$

1. School of Materials Science and Engineering, Beihang University, Beijing, 100191 P. R. China

2. Department of Chemical \& Biomolecular Engineering, University of Tennessee, Knoxville, Tennessee 37996, USA

3. Department of Biosystems Engineering and Soil Science, University of Tennessee, Knoxville, Tennessee 37996, USA

4. Department of Biosystems Engineering and Soil Science, University of Tennessee, Knoxville, Tennessee 37996, USA Department of Chemistry, University of Tennessee, Knoxville, Tennessee 37996, USA

5. Physical Chemistry of Materials Group, Oak Ridge National Laboratory, Oak Ridge, Tennessee 37831, USA

*Corresponding Author: tzawodzi@utk.edu. 


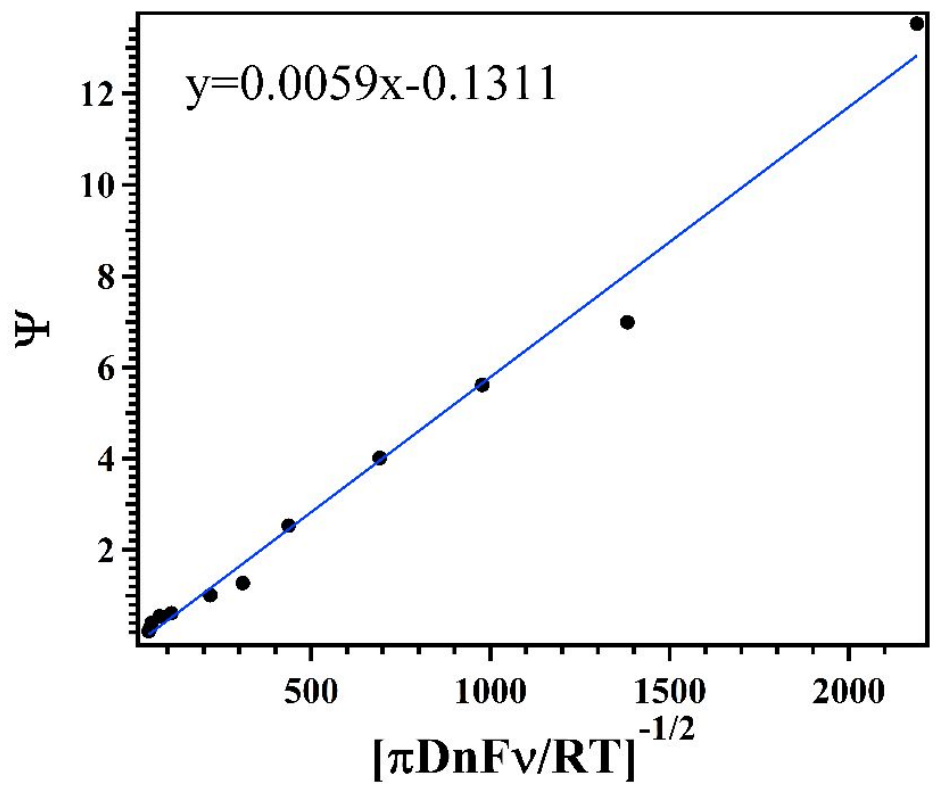

Figure S1. Plot of $\Psi$ vs. $[\pi \mathrm{DnF} v /(\mathrm{RT})]^{-1 / 2}$ for the oxidation of $2.44 \times 10^{-9} \mathrm{~mol} / \mathrm{L}$ Ferrocene in microemulsion with composition of $\mathrm{W} / \mathrm{S} / \mathrm{O}=58.1 / 36.9 / 5.0 \mathrm{w} / \mathrm{w} / \mathrm{w} \%$, with a glassy carbon electrode (3mm diameter).

Table S1. Peak separation, $\Delta E_{P}$, parameter $\Psi$ obtained from Equation (2) used to calculated heterogeneous electron transfer rate constant, $k^{0}$.

\begin{tabular}{ccc}
\hline Scan rate $\left(\mathrm{V} \mathrm{s}^{-1}\right)$ & $\Delta E_{P}(\mathrm{mV})$ & $\Psi$ \\
\hline 0.01 & 61 & 13.53 \\
0.025 & 63 & 6.99 \\
0.05 & 64 & 5.62 \\
0.1 & 66 & 4.02 \\
0.25 & 70 & 2.54 \\
0.5 & 80 & 1.28 \\
1 & 85 & 1.01 \\
4 & 99 & 0.62
\end{tabular}


8

16

18

20

22
103

115

128

137

145
0.55

0.41

0.31

0.26

0.22 